Ann. Geophysicae 14, 1186-1191 (1996) C EGS - Springer-Verlag 1996

\title{
Gravity wave signatures at mesopause heights
}

\author{
R. Rüster ${ }^{1}$, P. Czechowsky ${ }^{1}$, P. Hoffmann ${ }^{2}$, W. Singer ${ }^{2}$ \\ 1 Max-Planck-Institut für Aeronomie, Postfach 20, 37189 Katlenburg-Lindau, Germany \\ 2 Institut für Atmosphärenphysik der Universität Rostock, Schloßstraße 4-6, 18225 Kühlungsborn, Germany
}

Received: 18 March 1996/Revised: 5 June 1996/Accepted: 6 June 1996

\begin{abstract}
The ALOMAR SOUSY Radar operated at $53.5 \mathrm{MHz}$ has been used in a five-beam configuration to study dynamical processes at gravity wave periods in the summer polar mesosphere. A case study of a gravity wave with a period of about $9 \mathrm{~min}$ is presented and analysed in some detail. The three-dimensional wave number vector is determined from the phase information of the 9-min velocity oscillations obtained in all beam directions and all range gates. The horizontal wavelengths in the north and east direction are estimated to be about 60 and $50 \mathrm{~km}$, respectively. The echo power variations, simultaneously observed at different beam pointing positions, are investigated using cross-correlation analysis. The results show that these wave-associated variations lead to horizontal and vertical deformation of the echoing layers. The horizontal wavelength in the north-south direction, derived from the echo power modification, is in good agreement with the one obtained from the velocity analysis.
\end{abstract}

\section{Introduction}

It is well known that gravity waves play an important role in the dynamical behaviour of the middle atmosphere (e.g. Vincent, 1984; Reid, 1986; Vincent and Fritts, 1987). For studying these kind of processes at different temporal and spatial scales, VHF radars are powerful tools (e.g. Woodman and Guillen, 1974; Schmidt et al., 1979; Balsley and Gage, 1980; Tsuda et al., 1990; Rüster et al., 1986; Thomas et al., 1992). Using the ALOMAR SOUSY Radar (Singer et al., 1995), a successor of the mobile SOUSY VHF Radar (Czechowsky et al., 1984), measurements have been carried out near Andenes in northern Norway $\left(69^{\circ} \mathrm{N}, 16^{\circ} \mathrm{E}\right)$ in the summer of 1994 during the ECHO-94-Campaign (e.g. Lübken et al., 1996) to investigate gravity waves in the summer polar mesosphere. Preliminary results have been discussed by Rüster et al. (1995). The radar was operated at a frequency of $53.5 \mathrm{MHz}$, corresponding to a wavelength of about $6 \mathrm{~m}$. The peak pulse power used during the observational period was $150 \mathrm{~kW}$ and the duty cycle $4 \%$. The range resolution used in the measurements presented here was $300 \mathrm{~m}$. The phased antenna array consists of 148 four-element Yagis. The resulting main beam with a one-way-beam width of $6.5^{\circ}$ was sequentially steered into five independent positions: vertically $(\mathrm{V})$, and at $8^{\circ}$ off-zenith towards north $(\mathrm{N})$, east $(\mathrm{E})$, south $(\mathrm{S})$ and west (W). In each position measurements were made for about $6.4 \mathrm{~s}$ such that one cycle lasted $32 \mathrm{~s}$. The pulses were phase coded using a 16-bit complementary code.

\section{Observational results}

VHF radar echoes from the mesosphere at high latitudes in summer are known to be very strong (e.g. Carter and Balsley, 1982; Czechowsky et al., 1989; Rüster and Reid, 1990). These polar mesosphere summer echoes (PMSE) on average occur between about 80 and $90 \mathrm{~km}$, centred around $86 \mathrm{~km}$. An overview of the observations and a discussion of possible generation mechanisms is given by Cho and Kelley (1993). These PMSE greatly facilitate the continuous observation of gravity waves at mesopause heights. One particularly interesting example of such a wave event is presented in Fig. 1. It shows in a colour intensity plot the signal-to-noise ratio (upper panel) and the radial velocity (lower panel) as a function of height and time, obtained from measurements with a vertically pointing antenna beam. The echo intensity exhibits strong temporal and spatial variations, and the vertical velocity shows pronounced periodic oscillations with a period of about 9 min which will be subject to a subsequent detailed analysis.

\subsection{Wave structures in the velocity field}

The time series of the radial velocities measured in the vertically pointing beam are presented in Fig. 2. Velocities 


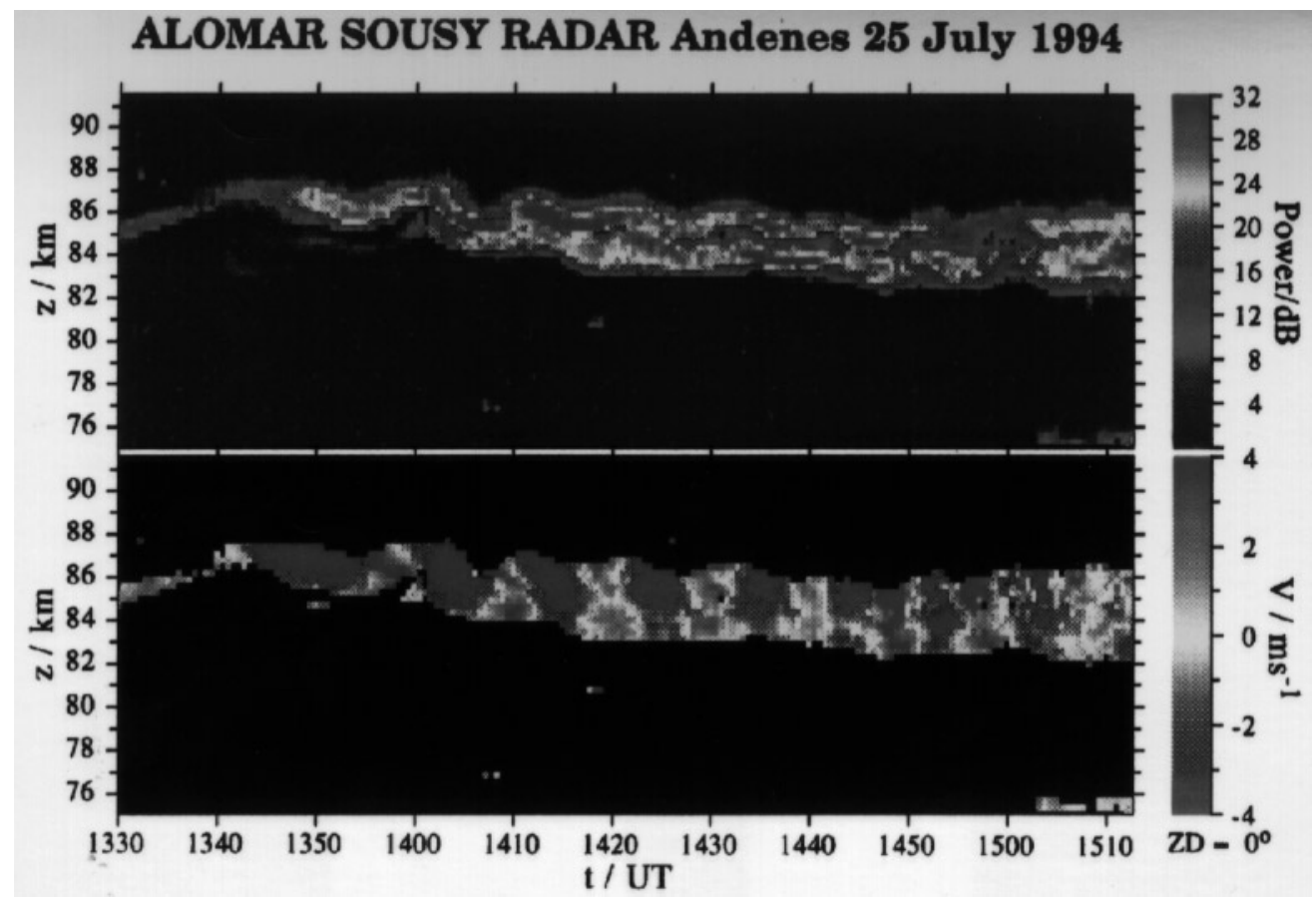

Fig. 1. Height-time intensity plots of the signal-to-noise ratio (upper part) and the radial velocity (lower part) measured in the vertically pointing beam

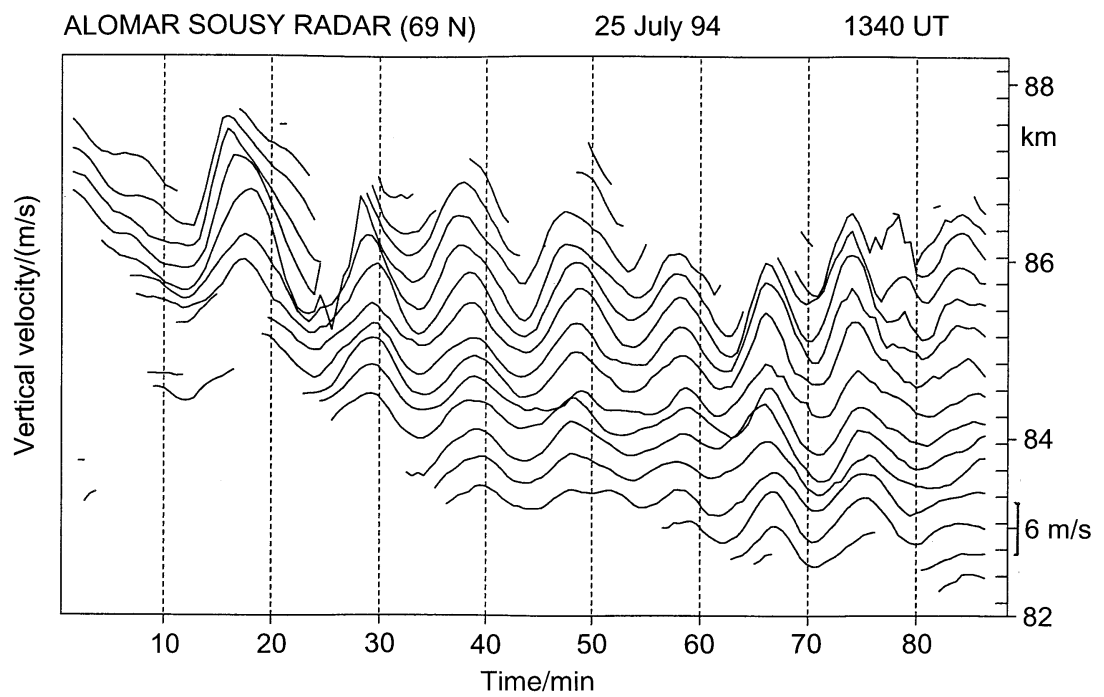

Fig. 2. Low-pass-filtered time series of the vertical velocity at heights between 82 and $88 \mathrm{~km}$, starting at 1340 UT (missing data are due to low signal-tonoise ratio) have only been derived from the measurements if the signal-to-noise ratio exceeded a level of $2 \mathrm{~dB}$. For reasons of clarity in the presentation the velocities have been low-pass filtered, with the 3-dB point of the filter being at $4 \mathrm{~min}$. Due to the filtering, parts of the original data are missing in this plot. The results clearly reveal the presence of periodic oscillations at all range gates. The phase progression with height indicates a propagating wave. In order to determine accurately the period of the wave, the maximum entropy method has been applied to the unfiltered velocity time series. As an example, Fig. 3 shows the resulting spectrum for a height of $86 \mathrm{~km}$. The dominating period is $9.6 \mathrm{~min}$. The same procedure has been used to analyse the respective measurements in the oblique beams, confirming the same wave period.
When studying the various wave parameters, the height variations of amplitude and phase of the wave are important quantities. Due to unavoidable gaps in the data, harmonic fitting procedures instead of Fourier transforms have been applied. Figure 4 shows the resulting height profiles of amplitude and phase of the 9.6-min wave, obtained from the original unfiltered data measured in the vertically pointing beam. The fitting procedure has been applied where at least $1 / 3$ of the data is available. This relatively low limit may influence the estimate of the amplitude but hardly the phase, as can be seen in Fig. 4. The decrease of the amplitude above about $86.2 \mathrm{~km}$, indicated by a dashed line, seems to be due to this effect. The phase, however, which later will be used for determining the wave number vector, seems not to be affected. 
An estimate of the atmospheric scale height $H$ in the mesopause region has been obtained by fitting an $\exp (z / 2 H)$-curve up to a height of $86.2 \mathrm{~km}$ to the amplitude profile shown in Fig. 4. The result of $H=5 \mathrm{~km}$ is in good agreement with other atmospheric observations (e.g. CIRA, 1972).

The dashed curve indicates the $90 \%$ confidence limits. They were calculated according to Bartels (1948) from a "Schütteltest" (shake test), in which the variance of the distribution of a certain Fourier component is obtained by randomly rearranging the original data. The phase resulting from this test, of course, will vary randomly with height. The results clearly show significant wave amplitudes up to heights of $87.5 \mathrm{~km}$. The same harmonic fitting procedure has also been applied to all data measured in the four oblique beams, confirming significant wave amplitudes at the respective range gates. From the total phase information $\phi(x, y, z)$ at all beams and all range gates, the three-dimensional wave number vector of the

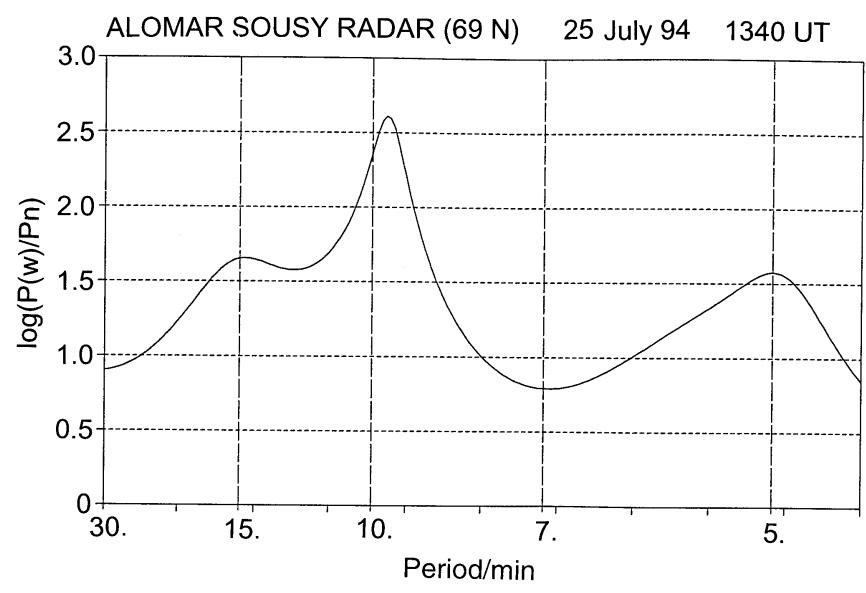

Fig. 3. Maximum entropy spectrum of the vertical velocity measured at a height of $86 \mathrm{~km}$ for the 90 -min observational period, starting at $1340 \mathrm{UT}$ 9.6-min wave is determined by a least squares fit of a single wave ansatz. By minimising $Q$ the three components of the wave number vector can be estimated:

$Q=\sum_{j}\left\{\phi\left(x_{j}, y_{j}, z_{j}\right)-\left(k_{x} x_{j}+k_{y} y_{j}+k_{z} z_{j}+\theta_{0}\right)\right\}^{2}$,

where $\theta_{0}=270^{\circ}$ at $z=83.5 \mathrm{~km}$ is taken from the results presented in Fig. 4, and $x, y, z$ refer to the eastward, northward and vertically upward direction, respectively. The resulting wavelengths in the eastward, northward and vertical direction are about 50,60 , and $-25 \mathrm{~km}$, respectively. The direction of the horizontal wave number vector, therefore, was about $50^{\circ}$, i.e. from southwest to northeast. The inclination in the vertical plane was about $60^{\circ}$.

In order to obtain an indication of the uncertainties with which the wavelength values may be associated, the total data set has been subdivided into three equal parts. For each the same analysis has been carried out, yielding three sets of wavelength values. The resulting standard deviations for the horizontal components are about $10 \mathrm{~km}$, and $20 \mathrm{~km}$ for the vertical component. This latter value, which does not affect the final conclusion, may result from the small height interval of $4 \mathrm{~km}$ only, as well as from the fact that the vertical wave number might be expected to vary with altitude at mesopause heights due to temperature changes. A division of the data set into more than three parts has not been chosen in order to avoid too short data sets for the sine fitting procedures. The results are further supported by a second approach in estimating the horizontal wavelength values by only using the respective phases from coplanar beam measurements.

\subsection{Associated variations in the radar echo intensity}

In addition to the wave-induced velocity oscillations discussed already, it is interesting to note that the signalto-noise ratio also undergoes spatial and temporal variations. Figure 5 presents in a colour intensity plot the signal-to-noise ratios as a function of height and time
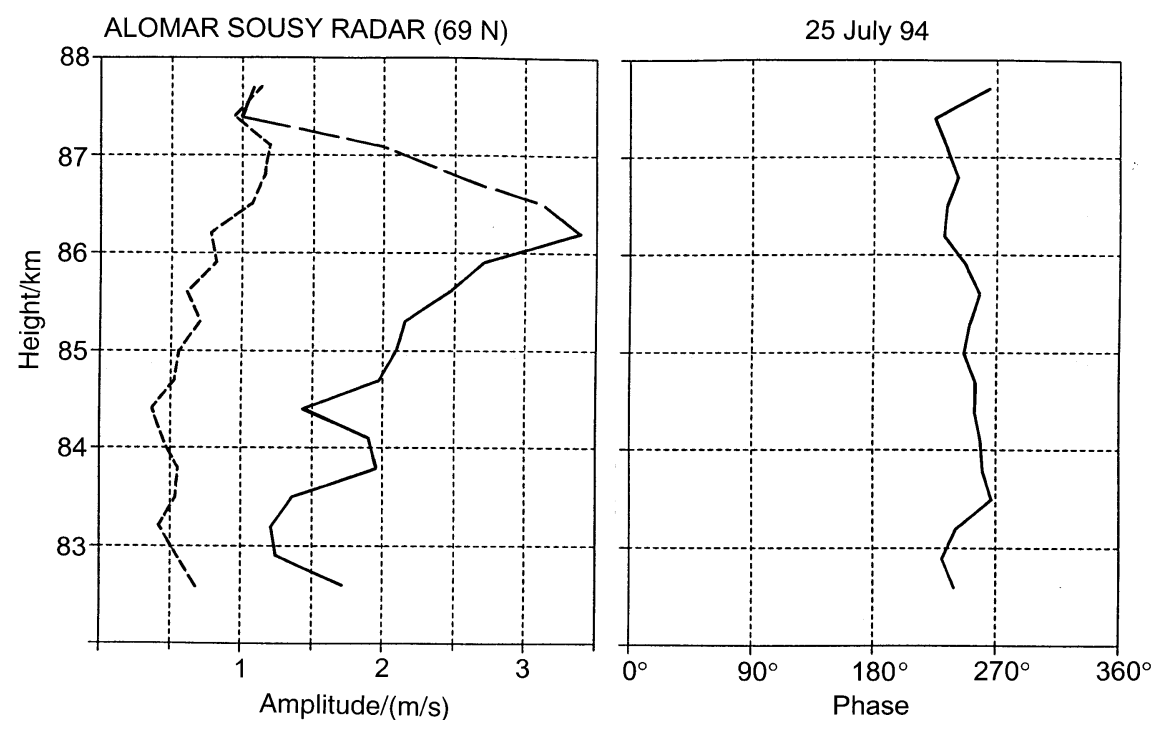

Fig. 4. Height profiles of amplitude and phase of the vertical velocity for the 9.6-min wave. The dashed curves represent the $90 \%$ significance levels 


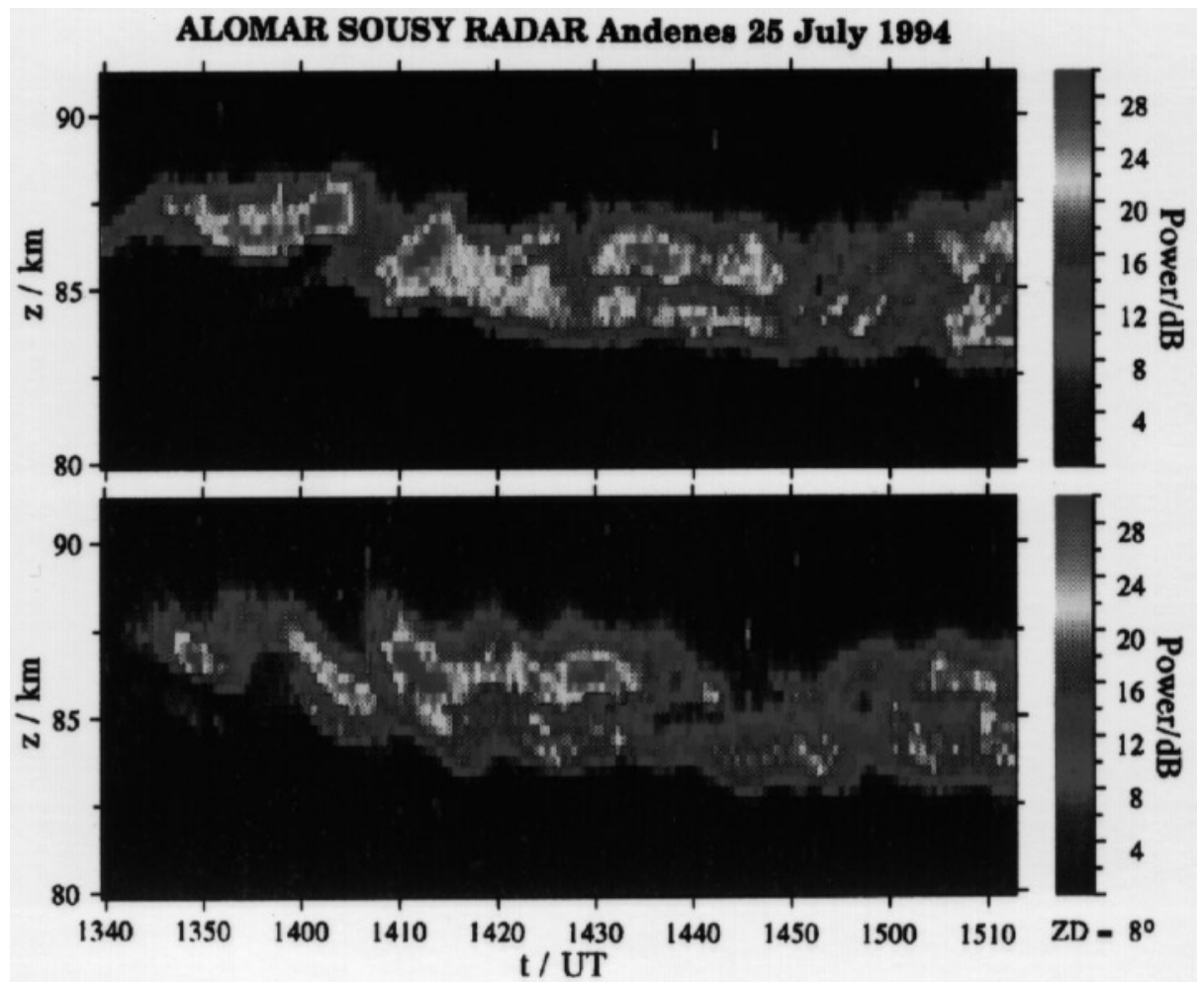

Fig. 5. Intensity plots of the signal-tonoise ratio as a function of height and time observed in the northward (upper part) and the southward (lower part) directed beam for the 90 -min observational period received in the northward (upper panel) and the southward (lower panel) pointing beam. By comparing both plots it becomes evident that the variations are approximately in antiphase. This relationship is particularly clear between about 1358-1405 UT, 1408-1415 UT, and 1418-1425 UT. During these periods the height of the peak intensities increases in the northward-pointing beam and at the same time decreases in the southward-pointing beam.

For a more accurate analysis the height $z_{\max }$ of the maximum signal-to-noise ratio has been determined for each time step and both beam directions. The results are shown in Fig. 6. Where $z_{\max }$ could not be determined unambiguously, no data are plotted. The periodic structure is -clearly visible, thereby reflecting the influence of the gravity wave on the temporal and spatial variation of the radar echo intensity. Apart from the gravity wave, additional temporal variations of different origin are superimposed, which may slightly mask the dominant 9.6-min oscillation. Additional confirmation of the suggested variation in the meridional plane is provided by the respective variation of the signal-to-noise ratio observed in the vertically pointing beam as shown in Fig. 1 (upper panel). The temporal variation of the height of the peak intensity fits between the respective curves for the northward- and southward-pointing beams shown in Fig. 6.

A possible, and most likely, explanation has been summarised schematically in Fig. 7. In order to demonstrate the effect more clearly the sketch is not to scale. The mesospheric echoing layers (or PMSE-structures) may undergo strong modifications by atmospheric waves as observed in the velocity field. If in particular, the distance

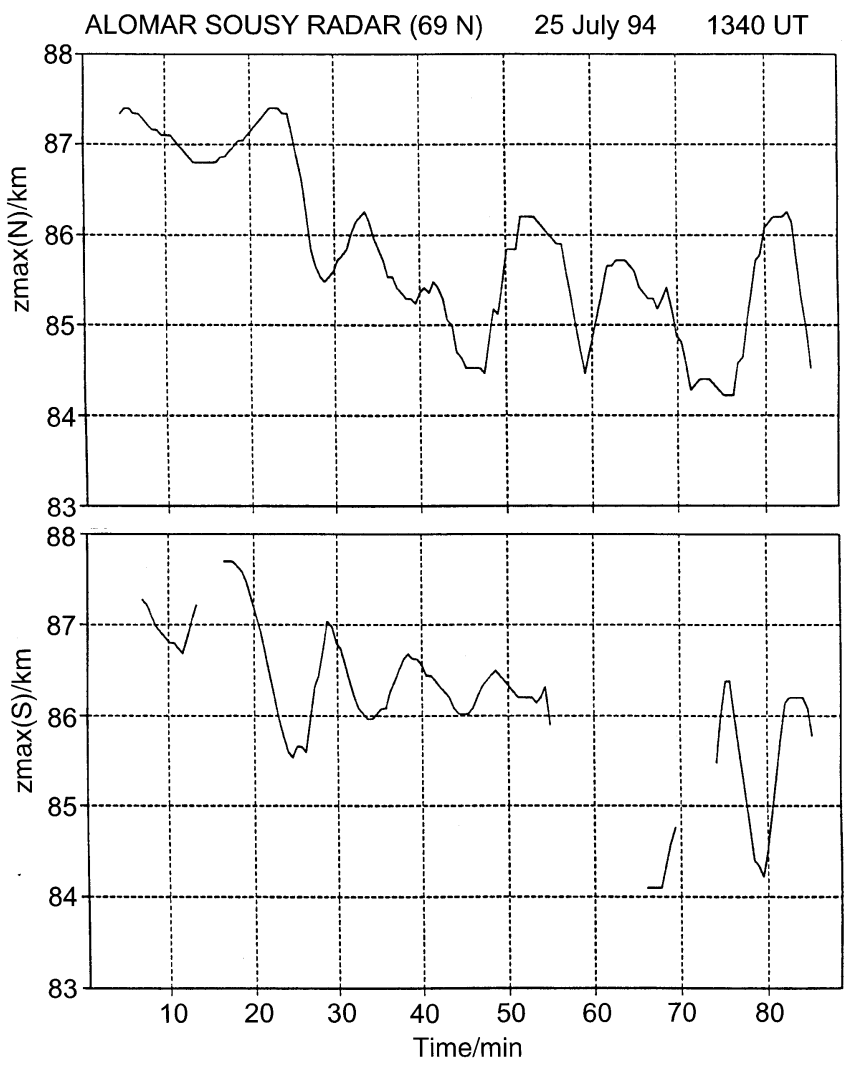

Fig. 6. Temporal variation of the height of the echo power maximum observed in the northward (upper part) and the southward (lower part) directed beam for the 90-min observational period, starting at $1340 \mathrm{UT}$ 


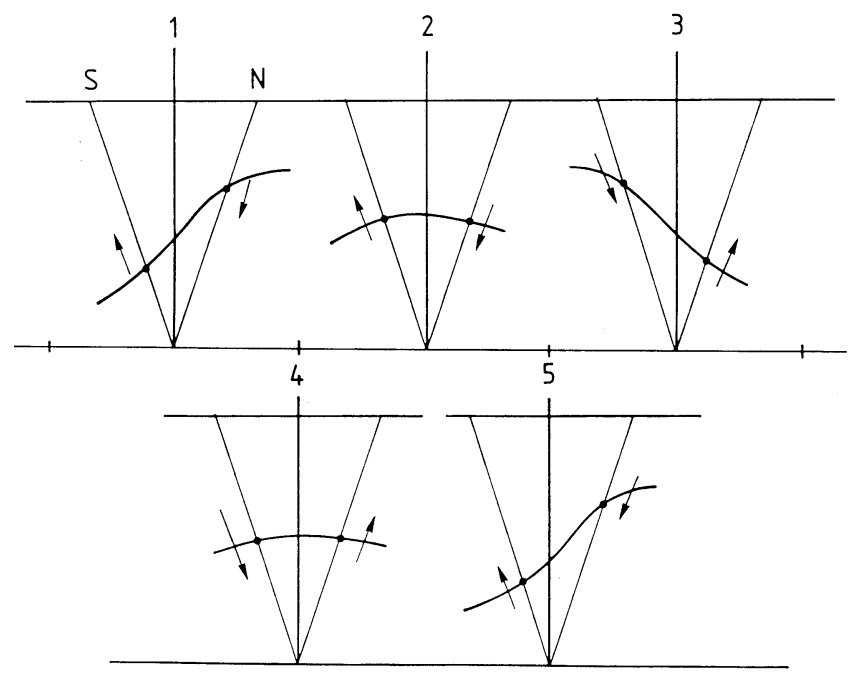

Fig. 7. Schematic sketch of the variation of the height of the echo power maximum in the meridional plane for five consecutive time steps

between two coplanar beams is comparable to half the horizontal wavelength, i.e., the phase differences are close to $180^{\circ}$, as observed, a bending of the layers may occur as shown in Fig. 7. Consequently, the height $z_{\max }$ at which the signal-to-noise ratio has its maximum may vary with the period of the wave, as demonstrated in the time steps 1 to 5 in the sketch. Figure 8 presents the cross-correlation function of the two time series $z_{\max }(t)$ shown in Fig. 6 for the time interval from 15 to 50 min after linear trends have been removed. From the distance $D$ between the two beams and the times of the minimum $\tau_{m i}$ and maximum $\tau_{m a}$ of the cross-correlation function, the horizontal wavelength $\lambda_{y}$ in this direction can be estimated:

$$
\frac{\lambda_{y}}{2}=\frac{D}{1+\frac{\tau_{m i}}{\tau_{m a}-\tau_{m i}}} .
$$

With $D=24 \mathrm{~km}, \tau_{m i}=-1.6 \mathrm{~min}$, and $\tau_{m a}=4.2 \mathrm{~min}$, the wavelength $\lambda_{y}$ in the meridional direction becomes $66 \mathrm{~km}$. This value is in good agreement with that of $60 \mathrm{~km}$, calculated from the phases of the velocities.

The maximum tilt angle $\chi_{m}$ of the layer can be estimated from

$\operatorname{tg} \chi_{m}=\frac{w_{0}}{\omega} k_{y}$

where $w_{0} \approx 2-3 \mathrm{~m} / \mathrm{s}$ is the average wave amplitude of the vertical velocity, $\omega$ the wave frequency $(2 \pi / T$; $T=9.6 \mathrm{~min}$ ) and $k_{y}$ the wave number in the north-south direction $\left(2 \pi / \lambda_{y} ; \lambda_{y}=60 \mathrm{~km}\right)$. The resulting angle of about $1^{\circ}$ is small compared to the radar beam width of $6.5^{\circ}$. Additional power variations due to tilt angle changes, therefore, are not significant.

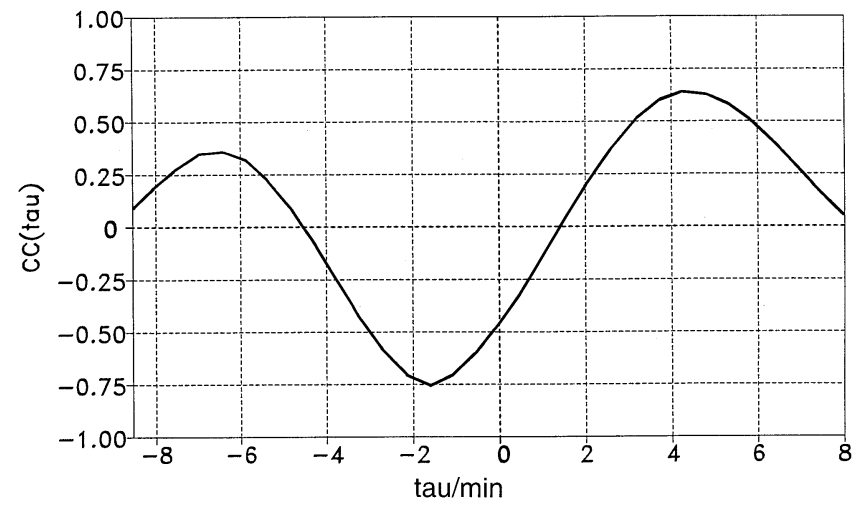

Fig. 8. Cross-correlation function of the two temporal variations shown in Fig. 6 for the time interval from 15 to $50 \mathrm{~min}$

\section{Concluding remarks}

Using multibeam configurations of VHF radars with at least five independent beam pointing positions, gravity waves in the velocity field, their signatures in the signal-tonoise ratios, as well as their possible interrelation can be studied in detail. They are frequently observed in the mesosphere and hence contribute essentially to the dynamical behaviour of the mesopause region (e.g. Vincent and Reid, 1983). Wave-induced perturbations of the echoing layers at mesopause heights observed with VHF radars can lead to strong asymmetries in the measurements obtained at coplanar beam pairs. The estimation of those quantities for which horizontal homogeneity is required (e.g. horizontal wind), therefore, can only be derived for averaging periods that are large enough compared to the respective wave periods.

Acknowledgements. The authors thank the staff of the Andoya Rocket Range as well as the engineers and technicians of the Institute for Atmospheric Physics and the Max-Planck-Institute for Aeronomy for their assistance in obtaining the radar measurements. Additional thanks are due to the referees for very valuable comments and to Dr. J. Klostermeyer for fruitful discussions.

Topical Editor F. Vial thanks L. Thomas and another referee for their help in evaluating this paper.

\section{References}

Balsley, B. B., and K. S. Gage, The MST radar technique: potential for middle atmospheric studies, Pure Appl. Geophys., 118, 452-493, 1980.

Bartels, J., Zufallszahlen für statistische Zwecke, Ann. Meteorol., 1, 209, 1948

Carter, D. A., and B. B. Balsley, The summer wind field between 80 and $93 \mathrm{~km}$ observed by the MST radar at Poker Flat, Alaska $\left(65^{\circ}\right.$ N), J. Atmos. Sci., 39, 2905-2915, 1982.

Cho, J. Y. N., and M. C. Kelley, Polar mesosphere summer radar echoes: observations and current theories, Rev. Geophys., 31, 243-265, 1993.

CIRA, COSPAR International Reference Atmosphere, Akademie, Berlin, 1972.

Czechowsky, P., G. Schmidt, and R. Rüster, The mobile SOUSY Doppler radar: technical design and first results, Radio Sci., 19, 441-450, 1984. 
Czechowsky, P., I. M. Reid, R. Rüster, and G. Schmidt, VHF radarechoes observed in the summer and winter polar mesosphere over Andoya, Norway, J. Geophys. Res., 94, 5199-5217, 1989.

Lübken, F.-J., K.-H. Fricke, and M. Langer, Noctilucent clouds and the thermal structure near the Arctic mesopause in summer, J. Geophys. Res., 101, 9489-9508, 1996.

Reid, I. M., Gravity-wave motions in the upper middle atmosphere (60-110 km), J. Atmos. Terr. Phys., 48, 1057-1072, 1986.

Rüster, R., and I. M. Reid, VHF radar observations of the dynamics of the summer polar mesopause region, J. Geophys. Res., 95, 10,005-10,016, 1990.

Rüster, R., J. Klostermeyer, and J. Röttger, SOUSY VHF radar measurements in the lower and middle atmosphere, IEEE Trans. Geosci. Remote Sensing, GE-24, 966 - 974, 1986.

Rüster, R., P. Czechowsky, P. Hoffmann, and W. Singer, First results of mesospheric structures and dynamics observed with the ALOMAR SOUSY radar, Proc. of the 12th ESA Symp., Lillehammer, ESA. sp-370, 67-71, 1995.

Schmidt, G., R. Rüster, and P. Czechowsky, Complementary code and digital filtering for detection of weak VHF radar signals from the mesosphere, IEEE Trans. Geosci. Electron, GE-17, 154-161, 1979.
Singer, W., D. Keuer, P. Hoffmann, P. Czechowsky, and G. Schmidt, The ALOMAR SOUSY radar: technical design and further developments, Proc. of the 12th ESA Symp., Lillehammer, ESA sp-370, 409-415, 1995.

Thomas, L., I. Astin, and I. T. Prichard, The characteristics of VHF echoes from the summer mesopause region at mid-latitudes, J. Atmos. Terr. Phys., 54, 969-977, 1992.

Tsuda, T., S. Kato, T. Yokoi, T. Inoue, M. Yamamoto, T. E. Van Zandt, S. Fukao, and T. Sato, Gravity waves in the mesosphere observed with the MU radar, Radio Sci., 26, 1005-1018, 1990.

Vincent, R. A., Gravity-wave motions in the atmosphere, J. Atmos. Terr. Phys., 46, 119-128, 1984.

Vincent, R. A., and D. C. Fritts, A climatology of gravity-wave motions in the mesopause at Adelaide, Australia, J. Atmos. Sci., 44, 748-760, 1987.

Vincent, R. A., and I. M. Reid, VHF Doppler measurements of mesospheric gravity wave momentum fluxes, J. Atmos. Sci., 40, 1321-1333, 1983.

Woodman, R. F., and A. Guillen, Radar observations of winds and turbulence in the stratosphere and mesosphere, J. Atmos. Sci., 31, 493-505, 1974. 